\title{
WO-2, a stable aneuploid derivative of Candida albicans strain WO-1, can switch from white to opaque and form hyphae
}

\author{
B. B. Magee and P. T. Magee \\ Author for correspondence: B. B. Magee. Tel: +1612625 4732. Fax: +1612625 5754 . \\ e-mail: bebe@biosci.cbs.umn.edu
}

Department of Genetics and Cell Biology, University of Minnesota, 1445 Gortner Avenue, St Paul, MN 55108, USA

\begin{abstract}
Candida albicans strain WO-2 was isolated as a spontaneous derivative of the white-opaque switching strain WO-1. The electrophoretic karyotype of WO-2 lacks two bands which are found in the parent. These bands correspond to one homologue of chromosome 7 and to a translocation product containing parts of chromosomes 6 and 5. Probing a blot of the karyotype demonstrated that the genetic material in these bands had been lost, yielding an aneuploid strain. UV-irradiation experiments showed that auxotrophs due to mutation in genes located in this region predominated, supporting the conclusion that WO-2 is partially haploid. WO-2 contained about $10 \%$ of its genome in the haploid state, and it grew with a doubling time of about twice that of its parent. However, it was able to undergo both the yeast-to-hyphal transition and the white-opaque transition. Hence, these processes do not require perfect diploidy.
\end{abstract}

Keywords: chromosome loss, aneuploidy, LEU2, HIS1, Candida albicans

\section{INTRODUCTION}

Although the opportunistic human pathogen Candida albicans has been the subject of intensive studies over the last 15 years, genetic approaches have been hampered by several peculiar properties of the organism (Scherer \& Magee, 1990). One is its lack of a sexual cycle; another is its diploid nature. The first precludes the use of classical genetic analysis to study the properties related to virulence and pathogenicity. The second makes molecular genetics much more cumbersome, since mutants made by classical means are likely to be non-isogenic with the parent strain, and gene deletions are difficult to make, requiring either two selectable markers or three recombination steps.

Some early studies suggested that most isolates contained many balanced recessive lethal mutations (Whelan \& Soll, 1982) and hence that diploidy was obligatory and that haploidy or even significant aneuploidy would not be possible. Evidence against this view was provided by the experiments of Barton \& Gull (1992), who showed that a strain could survive with only one copy of the $2 \mathrm{Mb}$ chromosome 3, although growth was slow until the aneuploid strain reduplicated the monosome, after which the growth rate was close to normal. However, the resulting strain was presumably now homozygous for one of the two original chromo- some 3 homologues, indicating that there were no recessive lethal mutations in at least one stretch of DNA comprising $6 \%$ of the diploid genome. Recessive lethal mutations thus seem to be rarer than first imagined.

Clinical isolates of $C$. albicans vary widely with respect to their electrophoretic karyotype (Magee et al., 1992; Iwaguchi et al., 1990). Furthermore, variation is often seen in laboratory strains, especially associated with changes in colony phenotypes (Suzuki et al., 1989; Rustchenko-Bulgac, 1991). While the major part of this variation is in chromosome $\mathrm{R}$ and is due probably to unequal crossing over in the ribosomal DNA repeats, new chromosomal bands frequently appear in both the large and the small size ranges. Many of these are due to translocations (Thrash-Bingham \& Gorman, 1992), but whether there are also deletions leading to aneuploid regions of the genome is not known.

If aneuploidy does occur naturally among C. albicans strains, it could have a significant role in pathogenesis, since it might allow the expression of recessive alleles important in the infection process. For example, many drug-resistance genes are recessive, and mutation of a hemizygotic allele to drug resistance would lead directly to the resistant phenotype.

It therefore seems important to investigate whether stable aneuploidy can exist in C. albicans and what its 
consequences are. In this paper, we show that a strain derived from the switching strain WO-1 is aneuploid, lacking $1.7 \mathrm{Mb} \mathrm{DNA}$, and that although its growth is affected it can still switch and make hyphae. Its aneuploidy makes it an attractive strain for examining the effects of mutations in the hemizygotic genes.

\section{METHODS}

Strains and plasmids. These are listed in Table 1.

Media and growth conditions. YEPD and minimal media were as described by Chu et al. (1992); cells were grown at $30^{\circ} \mathrm{C}$ on YEPD except when testing for nutritional markers, when appropriately supplemented minimal medium was used. Switching was observed on YEPD plates supplemented with phloxine $B$ and incubated at room temperature for 1 week or more. Hyphae were induced by incubation of cells in serum overnight at $37^{\circ} \mathrm{C}$.

PFGE. Chromosome sample plugs were made as described previously by Chu et al. (1993). Chromosomes were separated in $0.6 \%$ agarose gels (Amresco PFGE Grade III) in $0.5 \times \mathrm{TBE}$ buffer $(1 \times \mathrm{TBE}$ is $100 \mathrm{mM}$ Tris, $100 \mathrm{mM}$ boric acid, $2 \mathrm{mM}$ EDTA, pH 8.3), using the Bio-Rad CHEF-DRII. Conditions were $120-300 \mathrm{~s}$ for $24 \mathrm{~h}$ and $420-900 \mathrm{~s}$ for $48 \mathrm{~h}$ at $80 \mathrm{~V}$. Gels were blotted to nylon membranes (MSI Magnagraph) by standard Southern procedure or by a vacuum blotter (Bio-Rad model 785), and linked by UV (Bio-Rad GS Gene Linker).

Probes. Genes used as probes were excised from plasmids with restriction enzymes and run on agarose gels. Isolated fragments were purified by spinning through glass-wool (Heery et al., 1990), labelled with digoxigenin (Genius system ; BoehringerMannheim) and detected by chemiluminescence. Probes are listed in Table 1.

UV mutagenesis. Cells were spread on YEPD plates and mutagenized using the Bio-Rad GS Gene Linker at the 3 or
$4 \mathrm{~mJ}$ setting. Mutants were detected by replication to minimal medium.

Growth curves. Growth of the strains in YEPD at various temperatures was followed by cell count in a haemocytometer or by $\mathrm{OD}_{540}$ measurements in a Bausch \& Lomb Spectronic 70 spectrophotometer.

Transformation. Mutations were identified by transformation with known C. albicans genes. Transformation was by a standard spheroplast method available on the WorldWide Web Candida Information Page (http://alces.med.umn.edu/ Candida.html) (Magee, 1994) or by a whole-cell method using the Frozen-EZ Yeast Transformation kit (Zymo Research).

\section{RESULTS}

\section{Origin of strain WO-2}

Strain WO-2 was isolated from a culture of WO-1 which had been frozen at $-80^{\circ} \mathrm{C}$ in $7 \%$ DMSO for storage. Since WO-1 has a unique karyotype, it is always tested when recovered from frozen culture to make sure that no changes have occurred. In this case, the karyotype of all the colonies tested was significantly different from that of WO-1, although it was definitely not typical C. albicans (Fig. 1, lane 3; strain 1006). The karyotype of WO-1 (lane 2) is characterized by three reciprocal recombination products, between chromosomes 1 and 5 (both translocation products comigrate with chromosome 2), 4 and 7 (the translocation products are labelled 4.5 and 5), and 5 and 6 (one product comigrates with chromosome 4, and one is the smallest band) (Chu et al., 1993). The aberrant karyotype (lane 1) appeared to lack the reciprocal recombination product of chromosomes 5 and 6 that we call the supernumerary chromosome (snc), and the band corresponding to the unrearranged

\section{Table 1. Strains and plasmids}

\begin{tabular}{|c|c|c|}
\hline Strain/plasmid & Comments & Origin \\
\hline \multicolumn{3}{|l|}{ Strains } \\
\hline WO-1 & $\begin{array}{l}\text { White-opaque switching strain (Slutsky et al., 1987); carries three } \\
\text { translocations (Chu et al., 1993) }\end{array}$ & $\begin{array}{l}\text { D. Soll, University of Iowa, IA, } \\
\text { USA }\end{array}$ \\
\hline 1006 & Has a 'standard' C. albicans karyotype (Goshorn \& Scherer, 1989) & $\begin{array}{l}\text { A. Goshorn, Genetic Systems } \\
\text { Corporation, Redmond, USA }\end{array}$ \\
\hline \multicolumn{3}{|l|}{ Plasmids } \\
\hline $\mathrm{pVEC}$ & $\begin{array}{l}\text { Contains the C. albicans URA3 gene along with the ARS2 gene } \\
\text { in pUC18 (Goshorn } \text { et al., 1992) }\end{array}$ & $\begin{array}{l}\text { S. Grindle, University of } \\
\text { Minnesota, USA }\end{array}$ \\
\hline pRS425 & $\begin{array}{l}\text { Contains the } S . \text { cerevisiae } L E U 2 \text { gene in a } 2 \mu \text { plasmid } \\
\text { (Christianson } \text { et al., 1992) }\end{array}$ & $\begin{array}{l}\text { T. Christianson, Southern Illinois } \\
\text { University, USA }\end{array}$ \\
\hline pRM100 & $\begin{array}{l}\text { Contains the C. albicans URA3 and HIS1 genes together with } \\
\text { ARS2 and ARS3 (Pla et al., 1995) }\end{array}$ & $\begin{array}{l}\text { J. Pla, Universidad Complutense de } \\
\text { Madrid, Spain }\end{array}$ \\
\hline $\mathrm{pRC} 2312$ & $\begin{array}{l}\text { Contains the C. albicans URA3 and LEU2 genes in a vector } \\
\text { with ARS2 (Cannon } \text { et al., 1991) }\end{array}$ & $\begin{array}{l}\text { R. Cannon, University of Otago, } \\
\text { New Zealand }\end{array}$ \\
\hline pSTC7 & Contains the C. albicans HIS4 gene (Altboum et al., 1990) & E. Segal, Tel-Aviv University, Israel \\
\hline pAR84-3 & Contains the C. albicans HIS3 gene (Rosenbluh et al., 1985) & $\begin{array}{l}\text { J. Gorman, Bristol Myers Squibb, } \\
\text { Princeton, USA }\end{array}$ \\
\hline pILV2 & Contains the C. albicans ILV2 gene (Chu et al., 1993) & $\begin{array}{l}\text { J. Hicks, Hedral Corporation, } \\
\text { Portland, USA }\end{array}$ \\
\hline pARG4-1 & Contains the ARG4 gene in pEMBLY 23 (Hoyer et al., 1994) & B. Magee \\
\hline
\end{tabular}




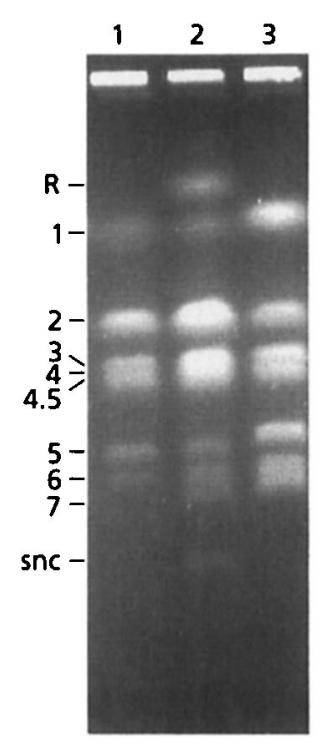

Fig. 1. PFGE separation of the chromosomes of C. albicans strains WO-2 (lane 1), WO-1 (lane 2) and 1006 (lane 3). Chromosomes are indicated on the figure. (a)

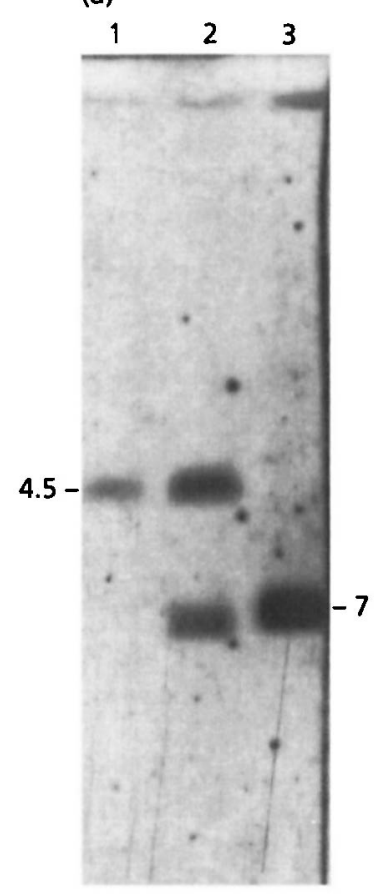

(b)

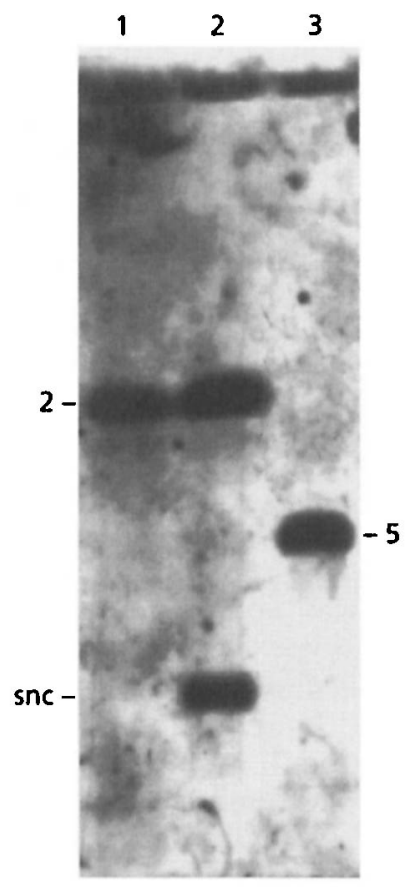

Fig. 2. Hybridization of chromosome-specific probes to a Southern blot of the gel in Fig. 1. (a) Probe LEU2, specific for chromosome 7; (b) probe 52-11, specific for fragment 5I. Lanes: 1 , WO- $2 ; 2$, WO- $1 ; 3,1006$. Chromosomes are indicated on the figure.

chromosome 7 was missing. All the other rearrangements appeared to be unchanged (see below). Although chromosome $\mathrm{R}$ varies from WO-1 to WO-2 in

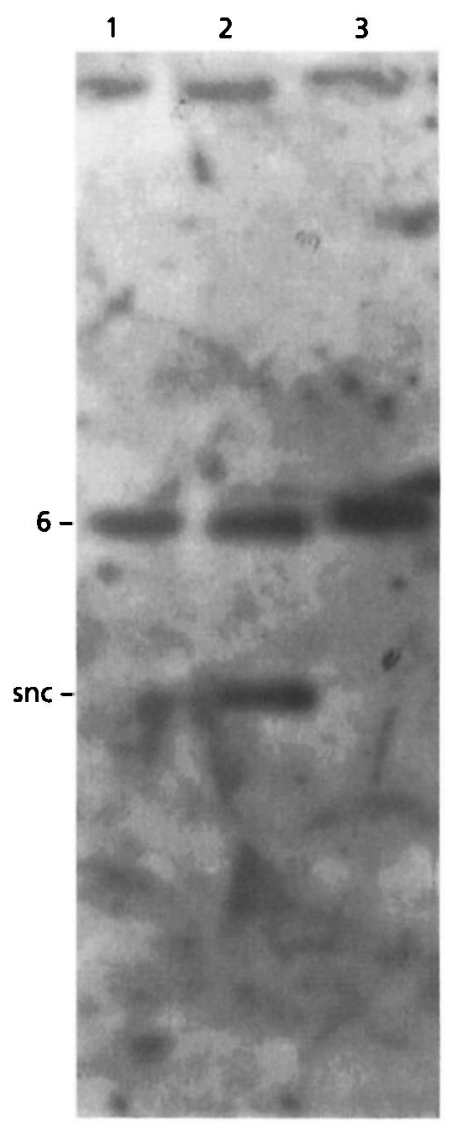

Fig. 3. Hybridization of 1631, a probe specific for chromosomal fragment $6 \mathrm{C}$, to a Southern blot of a gel as in Fig. 1. Lanes: 1, WO- $2 ; 2$, WO-1; 3, 1006. Chromosomes are indicated on the figure.

Fig. 1, this variation is due to unequal crossing over between sister chromatids and is quite common in $C$. albicans. The new strain, which we called WO-2, grew significantly more slowly than WO-1 (see below).

WO-1 is known to be cold-sensitive. Given the conditions under which WO-2 appeared and its apparent predominance in the frozen culture, it seemed possible that freezing and/or thawing in DMSO selected for this aneuploid state. However, repeated freezing and thawing of WO-1 failed to yield strains with any altered karyotypes. We therefore assume that WO-2 was a spontaneous variant of WO-1 and was inadvertently picked and used as the source for the frozen culture.

\section{Molecular analysis of the karyotype of WO-2}

Because of the relatively frequent chromosome rearrangements in C. albicans, similar electrophoretic mobility in a karyotype does not assure identity of bands. We therefore used a series of chromosomespecific markers to verify the altered karyotype of WO2. Fig. 2 shows the results of probing the blot in Fig. 1 with a marker specific for chromosome 7 (a) and one for fragment 5I (b). In Fig. 2(a), LEU2, a probe from the left 
wo-1

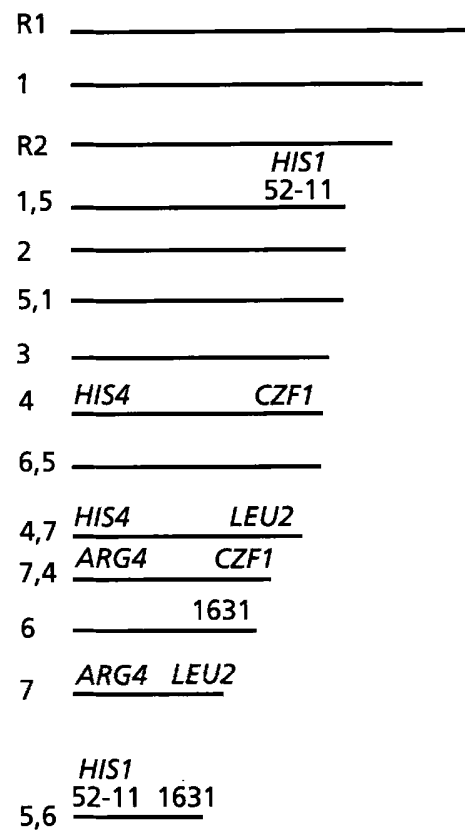

Wo-2

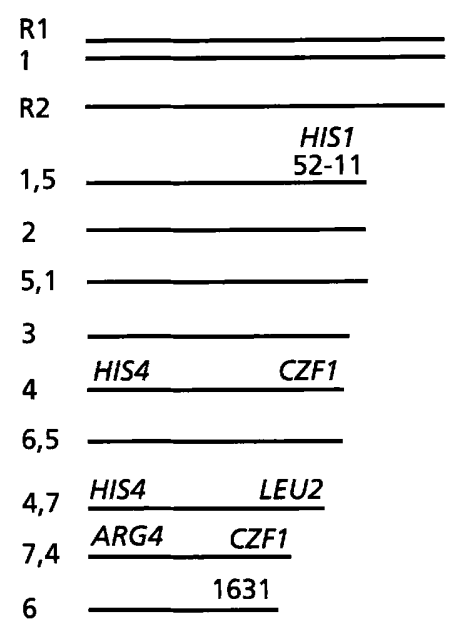

Fig. 4. Map of the karyotypes of WO-1 and WO-2. The map is based on that of Chu et al. (1993). The translocation chromosomes originally labelled $2,4,4.5,5$ and snc have been relabelled to indicate their composition. They are translocations 1,5 and 5,$1 ; 6,5 ; 4,7 ; 7,4 ;$ and 5,6 , respectively. The probes used to show the identities of various chromosome fragments are indicated above the chromosomes in their approximate locations. side of chromosome 7 , hybridizes with two bands in WO-1 (lane 2); these correspond to the intact chromosome (lower band) and to one of the 4,7 translocation products. In WO-2 (lane 1), the lower band is missing, as expected from the stained gel, but no new band has appeared. Fig. 2(b) shows the probe 52-11 from fragment 5I, which makes up part of the smallest chromosome fragment (a 5,6 translocation product) and part of a translocation product of chromosomes 1 and 5 in WO1. This probe therefore hybridizes to the small fragment and a large band in WO-1. In WO-2, 52-11 hybridizes only to the large band, while in 1006 (lane 3) it hybridizes to chromosome 5. Fig. 3 shows that 1631 , a probe specific for fragment $6 \mathrm{C}$, which makes up part of the 5,6 translocation product, hybridizes to two bands in WO1 (lane 2), but is found in WO-2 in only one band, that of the intact chromosome 6. In other experiments (not shown), probes demonstrated that the bands corresponding to chromosomes R, 2, 3 and 4 lie in the appropriate places on the electrophoretic karyotype of WO-2. Hence, this strain lacks one complete copy of chromosome 7 and in addition has only one copy of chromosome fragments $5 \mathrm{I}$ and 6C. Fig. 4 shows diagrams of the karyotypes of WO-1 and WO-2, with the positions of the chromosome-specific probes indicated.

\section{Growth and switching of WO-2}

The chromosome and chromosome fragments missing in WO-2 amount to about $1.7 \mathrm{Mb}$, or about $10 \%$ of the haploid genome. The loss of this amount of DNA might be expected to affect the growth characteristics of the aneuploid strain. WO-1 grows with a doubling time of $50 \mathrm{~min}$ at $37^{\circ} \mathrm{C}$ and $49 \mathrm{~min}$ at $30^{\circ} \mathrm{C}$. WO-2 grows with doubling times significantly slower; $85 \mathrm{~min}$ at $37{ }^{\circ} \mathrm{C}$ and $94 \mathrm{~min}$ at $30^{\circ} \mathrm{C}$. Although the differences in growth rate are quite noticeable on YEPD plates, WO-2 does not seem to give rise to faster-growing variants; the colony size of a culture of this strain is quite small but highly uniform.

WO-1 is the strain in which the white-opaque transition was discovered (Slutsky et al., 1987). The mechanism of this transition is still unknown, although a great deal has been discovered about the characteristics of the two phenotypes (Soll et al., 1993). McEachern \& Hicks (1991) found that the loss of the snc in WO-1 was accompanied by the loss of the capacity to switch. Chu et al. (1992) showed that in spheroplast fusants between switching and non-switching strains, retention of the snc was not required for retention of the switching phenotype. WO-2, although it grows slowly, nevertheless is capable of switching back and forth from the white to the opaque phenotype like WO-1 (Fig. 5a, c). In addition, it is able to make hyphae (Fig. 5b, d). (Under the conditions used here, incubation overnight in serum at $37^{\circ} \mathrm{C}$, WO-2 makes hyphae more abundantly than WO-1.) Thus, neither the snc nor indeed two copies of chromosome 7 are required for the white-opaque transition or for the yeast-to-hyphal transition.

\section{Isolation and characterization of mutants from WO-2}

The aneuploid nature of WO-2 predicts that mutations in genes found on the monosomic chromosomes should occur more frequently than mutations on other chromosomes and more frequently than in fully diploid C. albicans. The second prediction is difficult to test, since Candida strains vary widely in the ease with which 

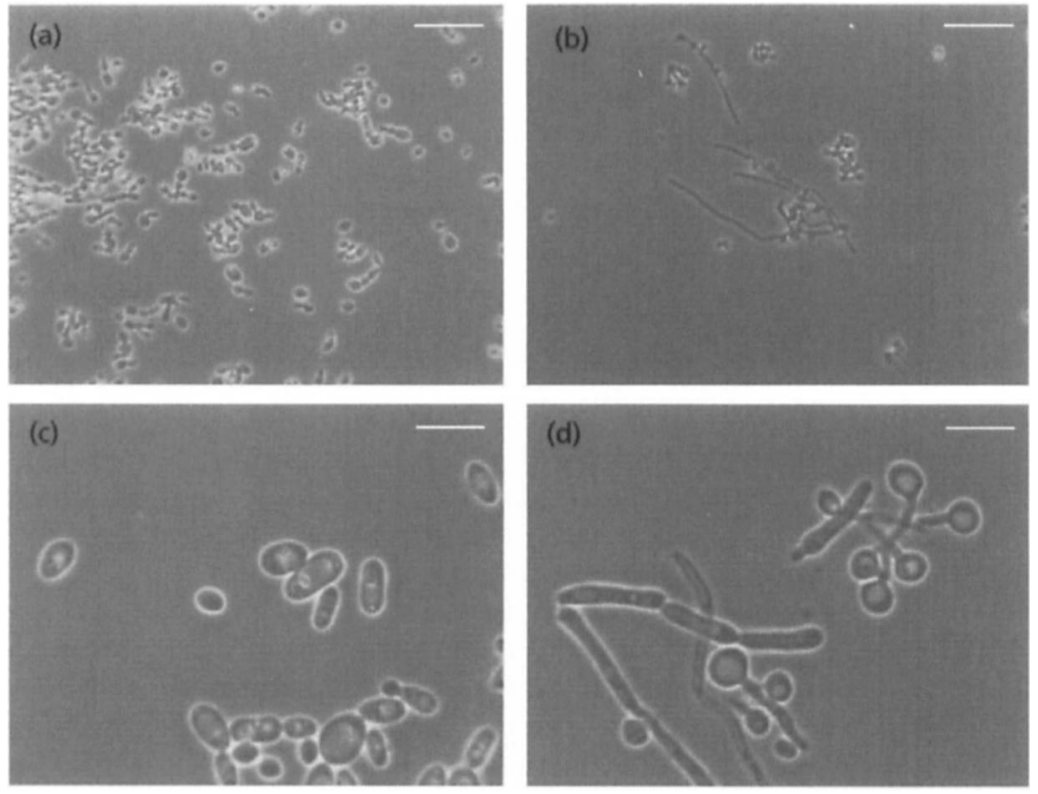

Fig. 5. Micrographs of WO-2. (a, c) A culture containing both white and opaque cells; (b, d) a culture containing hyphae. (a) Bar, $50 \mu \mathrm{m}$; (b) bar, $100 \mu \mathrm{m}$; (c, d) bars, $25 \mu \mathrm{m}$.
Table 2. Mutational analysis of WO-2

\begin{tabular}{|lccl|}
\hline Dose $(\mathrm{mJ})$ & $\begin{array}{c}\text { Total colonies } \\
\text { (percentage } \\
\text { survivors) }\end{array}$ & $\begin{array}{c}\text { No. of } \\
\text { auxotrophs }\end{array}$ & $\begin{array}{c}\text { Auxotroph } \\
\text { type }\end{array}$ \\
\hline Expt 1 & $353(35)$ & 0 & \\
2 & $205(14)$ & 2 & $\mathrm{Leu}^{-}, \mathrm{Thr}^{-}$ \\
3 & $88(4)$ & 1 & $\mathrm{Ilv}^{-}$ \\
4 & $36(1 \cdot 4)$ & 0 & \\
5 & $27(1 \cdot 1)$ & 1 & $\mathrm{Arg}^{-}$ \\
6 & & 2 & $\mathrm{Ilv}^{-}, \mathrm{His}^{-}$ \\
Expt 2 & $1033(54)$ & 0 & \\
3 & $366(19)$ & & \\
4 & $370(11)$ & 1 & $\mathrm{His}^{-}$ \\
\hline
\end{tabular}

they are mutagenized, and the isolation of stable mutations in WO-1 has proven to be quite difficult. However, in a mutagenesis experiment in WO-2, we would expect mutations in genes on chromosome 7 and on chromosome fragments $5 \mathrm{I}$ and $6 \mathrm{C}$ to predominate. Table 2 shows the results of UV-induced mutagenesis in WO-2. In experiment 1, increasing doses of UV from 2 to $6 \mathrm{~mJ}$ were used. The total number of auxotrophs isolated was 4 in 729 survivors, or $0.55 \%$. The spectrum of mutations was broad, with a single auxotroph each for leucine, arginine, threonine and isoleucine/valine occurring. In experiment 2 , two auxotrophs were found among 1033 survivors of $3 \mathrm{~mJ}$ of irradiation and none among 366 survivors of $4 \mathrm{~mJ}$; one of the auxotrophs was $\mathrm{Ilv}^{-}$and one was $\mathrm{His}^{-}$. In a third experiment, only a histidine requirer was found among 370 survivors of $3 \mathrm{~mJ}$ irradiation. Two amino acid biosynthetic genes are
Table 3. Transformation of WO-2 auxotrophs

\begin{tabular}{|llc|}
\hline $\begin{array}{l}\text { Mutant } \\
\text { phenotype }\end{array}$ & $\begin{array}{l}\text { Transformation } \\
\text { vector }\end{array}$ & $\begin{array}{c}\text { Prototrophic } \\
\text { transformants }\end{array}$ \\
\hline Leu $^{-}$ & pVEC-LEU1.9 & + \\
& pRC2312 & + \\
& pVEC-LEU & + \\
& pRS425 & + \\
His $^{-}$ & pRM100 (HIS1) & + \\
& pSTC7 (HIS4) & - \\
& pAR84-3 (HIS3) & - \\
$\mathrm{Ilv}^{-}$ & pILV2 & - \\
\hline
\end{tabular}

known to occur on chromosome 7:LEU2 and ARG4. HIS1 is found on chromosome fragment 5I.

In order to determine whether the new mutations are in fact in the genes known to be located in the haploid regions, we carried out transformations with LEU2-, $H I S$ - and ARG4-containing plasmids. Table 3, lines 1-3, shows that the $\mathrm{Leu}^{-}$mutant can be transformed to prototrophy with any of several plasmids containing the C. albicans LEU2 gene. More interestingly, it can also be transformed with the Saccharomyces cerevisiae LEU2 gene (line 4), thus making the latter one of the few foreign genes that function in C. albicans. Transformation of one of the $\mathrm{His}^{-}$mutants was attempted with the HIS1 gene as well as with the HIS3 and HIS4 genes. Only the HIS1 gene gave transformants (Table 3, lines 5-7). These plasmids have been shown to transform the appropriate C. albicans auxotrophs (Altboum et al., 1990; Pla et al., 1995; B. B. Magee, unpublished results). We used the ILV2 gene to transform the $\mathrm{Ilv}^{-}$auxotroph. No transformants were found. ILV2 is located on chromosome 3 . There should be three or four ILV genes 
in C. albicans, based on the results in S. cerevisiae, but only ILV2 has been cloned. Attempts to transform the $\mathrm{Arg}^{-}$strain with a plasmid containing ARG4 (pARG4-1) were not successful due to the leakiness of this mutation.

\section{DISCUSSION}

For an organism with no sexual cycle, the true state of ploidy is very hard to determine unequivocally. C. albicans was thought to be haploid for many years; it was not until it was shown to contain two alleles of several genes that investigators began to regard it as diploid (Whelan et al., 1980). However, that demonstration and the subsequent analysis of the complexity of genomic DNA (Riggsby et al., 1982) only indicated that it was largely diploid; neither method was sensitive enough to detect aneuploidy. The issue of partial haploidy (or triploidy) could not be settled by such experiments. Some early genetic experiments provided evidence for recessive lethal mutations (Whelan \& Soll, 1982); if these were common and balanced, the organism would not be able to tolerate extended regions of haploidy. The advent of PFGE of chromosomes (Snell \& Wilkins, 1986; Magee \& Magee, 1987) demonstrated that there is significant variation in the karyotype among clinical isolates, suggesting the possibility that chromosomes or parts of chromosomes were missing in some strains. Several of these aberrant karyotypes, however, were subsequently shown to be the result of translocations, with all or most of the chromosome material conserved (Thrash-Bingham \& Gorman, 1992).

Barton \& Gull (1992) showed that the organism could tolerate aneuploidy; they demonstrated that growth of an ade 2 heterozygote in the presence of methylbenzimidazol-2-yl carbamate led to small red ( $\mathrm{Ade}^{-}$) colonies; these slow-growing strains gave rise to progeny, still red and adenine-requiring, which grew much faster. Karyotypic analysis suggested that the cells in the small colonies had only one copy of chromosome $3(1.9 \mathrm{Mb}$ in size), the location of ade2, while the fastergrowing cells had two copies, presumably due to endoreduplication of the single chromosome 3 homologue in the original isolates. The fact that the monosomic strains were viable demonstrates that in this strain, at least, one homologue of the $3.8 \mathrm{Mb}$ chromosome 3 carries no recessive lethal mutations.

The results reported here show quite clearly that $C$. albicans strain WO-2 can grow, switch from white to opaque, and carry out the dimorphic transition while haploid for more than $1.5 \mathrm{Mb}$. The electrophoretic karyotype shows quite clearly that two bands present in the parent strain, WO-1, are missing; blots with genes present on these two chromosomes indicate that the missing information is not elsewhere on the karyotype as a result of further chromosome translocations.

One formal possibility for the changes that have occurred in WO-2 is that the chromosomes containing the genetic material in the missing bands have been duplicated, so that the strain, while still aneuploid, is not partially haploid but partially triploid. The mutagenesis experiments, while not ruling this out, make it very unlikely, since at least three of the seven auxotrophs isolated are due to mutations in genes with one allele on the missing bands; this is the expected result if the changes have left these genetic regions haploid. It will be interesting to determine whether there is an isoleucine/ valine biosynthetic gene in one of these regions, explaining why an $\mathrm{Ilv}^{-}$auxotroph was isolated twice in these experiments. The status of the $\mathrm{Arg}^{-}$mutation remains undetermined.

It is quite difficult to get stable mutations in WO-1; McEachern \& Hicks (1991) used an ade2 mutant generated by NTG treatment, and Chu et al. (1992) also used NTG to generate stable mutants. The genetic basis for this instability is unknown, but at least some UVinduced mutations in WO-2 are stable, in contrast to its parent. One possible explanation for this is that WO-1 has an elevated repair system that requires the homologous allele. If this is the case, the $\mathrm{Arg}^{-}$mutation may not lie in one of the haploid regions of the genome, but the $\mathrm{Ilv}^{-}$one probably does.

The low growth rate of WO-2 compared to its parent supports the idea that it is haploid for a significant amount of genomic material. Given the results of Barton \& Gull (1992), it is at first surprising that the aneuploid culture is not taken over by strains which have recovered diploidy or near diploidy. The most likely explanation is the fact that none of the missing chromosomes has an intact homologue in the karyotype. Thus, to return to a diploid level for chromosome 7, WO-2 would have to duplicate two translocation products, ending up triploid for chromosome 4, a $1.7 \mathrm{Mb}$ chromosome. For fragment 5I, a significant fraction of chromosome 1 would be triploid, and for fragment $6 \mathrm{C}, 900 \mathrm{~kb}$ of chromosome 6 would become triploid. Hence, WO-2 seems locked in an aneuploid, slow-growing state.

Since it is now clear that C. albicans can tolerate large regions of haploidy, at least for some parts of the genome, the question arises whether aneuploidy may play a role in its pathogenesis. Recessive genes whose expression is important for infection could be rendered hemizygous by the loss of a portion of a chromosome; if the loss were so great that growth were affected, reduplication as found by Barton \& Gull (1992) might lead to restoration of the wild-type generation time. Loss of one allele might also provide an opportunity for genetic variation, since any mutations in the hemizygous genes would be immediately expressed. It seems clear that diploidy without sex leads to significant genomic stability; however, variation would seem to be necessary for an organism that moves back and forth between commensalism and infection. Changes in ploidy, along with karyotypic rearrangement, may be a major mechanism by which C. albicans achieves genetic variability.

\section{ACKNOWLEDGEMENTS}

We would like to thank Caroline Wenner for growth curves and Stewart Scherer for helpful discussions. This work was 
supported by USPHS grants R01-AI16567 and R01-AI35109 awarded to P.T.M.

\section{REFERENCES}

Altboum, Z., Gottlieb, S., Lebens, G. A., Polacheck, I. \& Segal, E. (1990). Isolation of the Candida albicans histidinol dehydrogenase (HIS4) gene and characterization of a histidine auxotroph. $J$ Bacteriol 172, 3898-3904.

Barton, R. C. \& Gull, K. (1992). Isolation, characterization, and genetic analysis of monosomic, aneuploid mutants of Candida albicans. Mol Microbiol 6, 171-177.

Cannon, R. D., Jenkinson, H. F. \& Shepherd, M. G. (1991). Isolation and nucleotide sequence of an autonomously replicating sequence (ARS) element functional in Candida albicans and Saccharomyces cerevisiae. Mol Gen Genet 221, 210-228.

Christianson, T. W., Sikorski, R. S., Dante, M., Shero, J. H. \& Hieter, P. (1992). Multifunctional yeast high-copy-number shuttle vectors. Gene 110, 119-122.

Chu, W. S., Rikkerink, E. H. \& Magee, P. T. (1992). Genetics of the white-opaque transition in Candida albicans: demonstration of switching recessivity and mapping of switching genes. J Bacteriol 174, 2951-2957.

Chu, W. S., Magee, B. B. \& Magee, P. T. (1993). Construction of an $S f i$ macrorestriction map of the Candida albicans genome. $J$ Bacteriol 175, 6637-6651.

Goshorn, A. K. \& Scherer, S. (1989). Genetic analysis of prototrophic variants of Candida albicans. Genetics 123, 667-673.

Goshorn, A. K., Grindle, S. M. \& Scherer, S. (1992). Gene isolation by complementation in Candida albicans and applications to physical and genetic mapping. Infect Immun 60, 876-884.

Heery, D. M., Gannon, F. \& Powell, R. (1990). A simple method for subcloning DNA fragments from gel slices. Trends Genet 6, 173.

Hoyer, L. L., Magee, B. B., Rikkerink, E. H. \& Scherer, S. (1994). The ARG4 gene of Candida albicans. Gene 142, 213-218.

Iwaguchi, S., Homma, M. \& Tanaka, K. (1990). Variation in the electrophoretic karyotype analysed by the assignment of DNA probes in Candida albicans. J Gen Microbiol 136, 2433-2442.

McEachern, M. J. \& Hicks, J. B. (1991). Dosage of the smallest chromosome affects both the yeast-hyphal transition and the white-opaque transition of Candida albicans WO-1. J Bacteriol 173, 7436-7442.

Magee, B. B. (1994). Formation of Candida albicans spheroplasts. In Molecular Biology of Pathogenic Fungi: a Laboratory Manual, pp. 113-115. Edited by B. Maresca \& G. S. Kobayashi. New York: Telos Press.

Magee, B. B. \& Magee, P. T. (1987). Electrophoretic karyotypes and chromosome numbers in Candida species. J Gen Microbiol 133, 425-430.

Magee, P. T., Bowdin, L. \& Staudinger, J. (1992). Comparison of molecular typing methods for Candida albicans. J Clin Microbiol 30, 2674-2679.

Pla, J., Perez-Diaz, R. M., Navarro-Garcia, F., Sanchez, M. \& Nombela, C. (1995). Cloning of the Candida albicans HIS1 gene by direct complementation of a C. albicans histidine auxotroph using an improved double-ARS shuttle vector. Gene 165, 115-120.

Riggsby, W. S., Torres-Bauza, L. S., Wills, J. H. \& Townes, T. M. (1982). DNA content, kinetic complexity, and the ploidy question in Candida albicans. Mol Cell Biol 2, 853-862.

Rosenbluh, A., Mevarech, M., Koltin, Y. \& Gorman, J. (1985). Isolation of genes from Candida albicans by complementation in Saccharomyces cerevisiae. Mol Gen Genet 200, 500-502.

Rustchenko-Bulgac, E. P. (1991). Variations of Candida albicans electrophoretic karyotypes. J Bacteriol 173, 6586-6596.

Scherer, S. \& Magee, P. T. (1990). Genetics of Candida albicans. Microbiol Rev 54, 226-241.

Slutsky, B., Staebell, M., Anderson, J., Risen, L., Pfaller, M. \& Soll, D. R. (1987). 'White-opaque transition': a second high-frequency switching system in Candida albicans. J Bacteriol 169, 189-197.

Snell, R. G. \& Wilkins, R. J. (1986). Separation of chromosomal DNA molecules from C. albicans by pulsed field electrophoresis. Nucleic Acids Res 14, 4401-4406.

Soll, D. R., Morrow, B. \& Srikantha, T. (1993). High-frequency phenotypic switching in Candida albicans. Trends Genet 9, $61-65$.

Suzuki, T., Kobayashi, I., Kanbe, T. \& Tanaka, K. (1989). High frequency variation of colony morphology and chromosome reorganization in the pathogenic yeast Candida albicans. J Gen Microbiol 135, 425-434.

Thrash-Bingham, C. \& Gorman, J. A. (1992). DNA translocations contribute to chromosome length polymorphisms in Candida albicans. Curr Genet 22, 93-100.

Whelan, W. L. \& Soll, D. R. (1982). Mitotic recombination in Candida albicans: recessive lethal alleles linked to a gene required for methionine biosynthesis. Mol Gen Genet 187, 477-485.

Whelan, W. L., Partridge, R. M. \& Magee, P. T. (1980). Heterozygosity and segregation in Candida albicans. Mol Gen Genet $180,107-113$.

Received 21 August 1996; revised 30 September 1996; accepted 8 October 1996. 